nephron

Practice
Nephron 2019;143:153

DOI: $10.1159 / 000503790$
Received: September 30, 2019

Accepted: September 30, 2019

Published online: October 8, 2019

\title{
Changing Paradigms in Acute Kidney Injury: From Mechanisms to Management: Proceedings of the 9th Annual UAB-UCSD O'Brien Center Symposium
}

\author{
Kelly K. Andringa ${ }^{a}$ Ravindra L. Mehta ${ }^{c}$ Paul W. Sanders ${ }^{a}, b$ \\ Anupam Agarwal ${ }^{\mathrm{a}, \mathrm{b}}$ \\ ${ }^{a}$ Division of Nephrology, Department of Medicine, University of Alabama at Birmingham, Birmingham, AL, USA; \\ ${ }^{b}$ Department of Veterans Affairs Medical Center, Birmingham, AL, USA; 'Division of Nephrology, Department of \\ Medicine, University of California, San Diego, CA, USA
}

Acutekidney injury(AKI) is the sudden onset of kidney failure or kidney damage that occurs within hours or up to a few days. This causes immediate buildup of waste products in the blood and leads to the inability to maintain appropriate fluid balance in the body. The recent research surrounding this disease state has attempted to further detail the mechanisms of AKI, how they affect other organ systems but has also been focused on therapeutic and preventative strategies for AKI. Preventative strategies have come to the forefront through the interest in precision medicine and how it can best be utilized in AKI. Targets for cellular and physiological intervention have also been involved in the research in this field as well as other disease states that lead to AKI in patient populations. This issue summarizes the proceedings of the 9 th annual symposium that was sponsored by the University of Alabama at Birmingham-University of California San Diego O'Brien Center for AKI Research and held during the 24th annual Continuous Renal Replacement Therapy conference in San Diego, California, on February 26, 2019.

The overall goal of this symposium was to provide a comprehensive review of the most recent developments in the study of AKI and describe emerging knowledge from basic and translational research. The meeting included 20 experts invited from around the world and over 100 participants were in attendance. Symposium sessions focused on defining key molecules, mechanisms, and targets involved in the pathogenesis, transition of disease, and re-

\section{KARGER}

(c) 2019 S. Karger AG, Basel

E-Mail karger@karger.com

www.karger.com/nef pair involved in AKI. The symposium included discussion of how to best utilize animal model results in AKI studies and coordinate that to the human condition. Sections further addressing the ability to move human trials and human data into treatment paradigms and the different issues arising in treatment, research and diagnosis of AKI.

The University of Alabama at Birmingham-University of California San Diego O'Brien Center has taken a major role in the development and availability of scientific and clinical resources for investigators performing AKI-related research. The Center has been involved in identifying research trends, emerging technologies, and assisting in the pursuit of opportunities through enhanced core resources, training on techniques, and added to the educational opportunities through workshops and seminars. This symposium highlights the exciting developments in the field and provided a forum for exchange of ideas among basic scientists, clinicians, and others interested in AKI. The proceedings from this symposium provide a unique collection that we anticipate will stimulate further interest in delving further into the mechanistic causes, treatment of disease, and outcomes of research and those populations related to AKI.

\section{Disclosure Statement}

The authors have no conflicts of interest to disclose. 